\title{
NOVAS METODOLOGIAS DE ENSINO? O DISCURSO DO SUJEITO COLETIVO DE UMA TURMA DE ADMINISTRAÇÃO
}

\author{
NEW TEACHING METHODS? DISCOURSE OF THE COLLECTIVE SUBJECT OF A CLASS ON THE \\ BUSINESS ADMINISTRATION COURSE
}

¿NUEVAS METODOLOGÍAS DE ENSEÑANZA? EL DISCURSO DEL SUJETO COLECTIVO DE UNA CLASE DE ADMINISTRACIÓN

\author{
ROBERTO FLORES FALCÃO \\ Doutorando \\ Universidade de São Paulo - Brasil \\ titofalcao@usp.br
}

KAVITA MIADAIRA HAMZA

Doutora

Universidade de São Paulo - Brasil kavita@usp.br

\author{
ANDRES RODRIGUEZ VELOSO \\ Doutor \\ Universidade de São Paulo - Brasil \\ veloso@usp.br
}

MARCOS CORTEZ CAMPOMAR

Doutor

Universidade de São Paulo - Brasil campomar@usp.br

Submetido em: 19/12/2016 Aprovado em: 13/09/2017

Doi: alcance.v24n3.p445-459

\section{RESUMO}

As recentes mudanças tecnológicas e no perfil dos alunos vêm levando escolas e professores a repensar suas estratégias e técnicas de ensino. Surgem diversas propostas, com destaque para as metodologias ativas de ensino. Contudo, faz-se necessária a verificação se os alunos efetivamente anseiam e se sentem confortáveis com novas dinâmicas em sala de aula. Nesse contexto, o presente artigo investiga como os alunos lidam com metodologias ativas de ensino. Para tanto, o depoimento individual de 52 alunos de um Curso de Administração foi coletado por meio de questionário com questões abertas. Analisando o conteúdo, por meio do método do Discurso do Sujeito Coletivo (DSC) e com apoio de um software de análise qualitativa, conclui-se que é necessária parcimônia na reformulação das estratégias de ensino. Mudanças drásticas podem prejudicar o processo de aprendizagem e a heterogeneidade da sala deve ser respeitada. O DSC foi selecionado, pois ele busca iluminar o campo social pesquisado, procurando entender o que pensa um conjunto específico de pessoas e analisar 0 significado de algum contexto para tal grupo. Por meio dele, o coletivo é reconstituído a partir da opinião de um conjunto de discursos na primeira pessoa do singular. Com base nos dados coletados, também é proposta uma classificação do perfil dos alunos com base em duas dimensões abstratas extraídas dos próprios discursos individuais.

Palavras-chave: Ensino de administração. Metodologia de ensino. Discurso do Sujeito Coletivo. 


\section{ABSTRACT}

Recent technological changes, and a shift in the student's profile, have led schools and teachers to rethink their strategies and teaching techniques. Several proposals have emerged, with emphasis on active teaching methodologies. However, it needs to be determined whether students effectively want, and feel comfortable with the new classroom dynamics. In this context, this paper investigates how students view active teaching methodologies. For this purpose, the individual testimonies of 52 students of a course in business administration were collected through a questionnaire with open questions. Analyzing the content, through the method of the discourse of the collective subject (DCS) and with the support of a qualitative analysis software program. The research concluded that caution is needed in the reformulation of teaching strategies, as drastic changes can hamper the learning process, and the heterogeneity of the classroom should be respected. DCS was chosen because it seeks to illuminate the social field researched, attempting to understand the thinking of a specific group of people, and to analyze the meaning of a certain context for this group. Through this means, the collective is reconstituted based on the opinions given in a set of first-person discourses. From the data collected, a classification of the student's profile is proposed, based on two abstract dimensions taken from the individual discourses themselves.

Keywords: Management education. Teaching methodology. Discourse of the Collective Subject.

\section{RESUMEN}

Los recientes cambios tecnológicos y en el perfil de los alumnos están llevando a las escuelas y profesores a repensar sus estrategias y técnicas de enseñanza. Surgen diversas propuestas, con destaque para las metodologías activas de enseñanza. Con todo, se hace necesario verificar si los alumnos efectivamente desean y se sienten cómodos con las nuevas dinámicas en el aula. En ese contexto, el presente artículo investiga cómo los alumnos aceptan las metodologías activas de enseñanza. Para ello, se recogió el testimonio individual de 52 alumnos de un Curso de Administración por medio de un cuestionario con preguntas abiertas. Analizando el contenido por medio del método del Discurso del Sujeto Colectivo (DSC) y con el apoyo de un software de análisis cualitativo, se concluye que es necesario tener parsimonia en la reformulación de las estrategias de enseñanza. Los cambios drásticos pueden perjudicar el proceso de aprendizaje y se debe respetar la heterogeneidad de la clase. Se seleccionó el DSC pues el mismo busca iluminar el campo social investigado, intentando entender lo que piensa un conjunto específico de personas y analizar el significado de algún contexto para tal grupo. Por medio del mismo, el colectivo es reconstituido a partir de la opinión de un conjunto de discursos en primera persona del singular. A partir de los datos recolectados, también se propone una clasificación del perfil de los alumnos con base en dos dimensiones abstractas extraídas de los propios discursos individuales.

Palabras clave: Enseñanza de administración; Metodología de enseñanza; Discurso del Sujeto Colectivo.

\section{INTRODUÇÃO}

É inegável e irreversível a mudança no perfil dos alunos e em sua expectativa com relação à sala de aula, tanto quanto ao conteúdo das aulas quanto à forma como as mesmas são conduzidas. Associado a este fato, 0 acesso ao conhecimento foi drasticamente ampliado e democratizado por meio de novas mídias e especialmente novas tecnologias. Qualquer cidadão conectado à internet tem acesso em tempo real a uma imensidão de dados. O conhecimento deixou de ser propriedade de poucos, impondo uma nova relação de ensino-aprendizagem nos espaços de aula, bem como um novo papel ao professor. A mera transferência de conhecimento não é mais suficiente para o desempenho de suas atividades.

De acordo com Paulo Freire, é necessário repensar o modelo de educação bancária. "Ensinar não é transferir conhecimento, mas sim criar possibilidades ao educando para formação ou construção desse conhecimento" (FERRARI, n.d.). A pressão por parte dos alunos e da sociedade por novas metodologias de ensino pode ser sentida em qualquer nível, do ensino fundamental à pós-graduação, exigindo do professor um novo aparato pessoal e tecnológico. Seja por meio da avaliação das disciplinas e dos docentes feita pelos alunos, em reuniões de pais e mestres ou mesmo em conversas informais no corredor das instituições de ensino, é uníssona a opinião dos alunos: aulas puramente teóricas e expositivas são enfadonhas e não estimulam a efetiva aprendizagem. 
Nesse contexto, surge a preocupação com a aprendizagem significativa dos alunos e ganham espaço as metodologias ativas. Como tentativa de incluir o aluno ativamente no processo de ensino-aprendizagem, diluindo a responsabilidade pela aprendizagem entre todos os agentes, instituições e docentes vêm repensando suas matrizes curriculares e o papel do professor dentro e fora de sala de aula. Ao mesmo tempo, surgem empresas de tecnologia, de consultoria e de capacitação docente que buscam algum espaço nessa (r)evolução cada vez mais significativa.

A partir dessa realidade, no segundo semestre de 2015, decidiu-se remodelar uma disciplina da área de marketing oferecida aos alunos do curso de Administração da Faculdade de Economia, Administração e Contabilidade da Universidade de São Paulo. Mantendo e respeitando a ementa da disciplina, cujo objeto de estudo é o comportamento do consumidor, foi elaborado um programa que envolvesse mais o aluno com 0 conteúdo, que evidenciasse a aplicação dos conteúdos na prática, que minimizasse a sensação de "perda de tempo" em sala de aula por parte dos discentes e que oferecesse maior liberdade e responsabilidade dos alunos com relação ao conteúdo teórico. Optou-se por um desenho de sala de aula invertida, em que os alunos deveriam estudar o conteúdo teórico antes das aulas, para que, em cada encontro, o conteúdo fosse abordado de forma prática e aplicada. Assim, em cada sessão da disciplina foi convidado um profissional de mercado cuja atuação tivesse relação com o tema de estudo da aula. Em função da agenda dos palestrantes, foi criado um planejamento e estruturado o programa da disciplina, contendo aula a aula: o tema a ser discutido, o respectivo capítulo do livro base e o palestrante. Para encorajar a classe a entrar em contato com o tema e a teoria antes de cada encontro, para cada aula os alunos, em grupos, deveriam entregar, no início da aula, uma breve resenha de uma lauda sobre um artigo acadêmico indicado pela professora. Para reforçar ainda mais a leitura crítica, a resenha deveria conter as impressões sobre o tema e sobre a pesquisa, uma sugestão para estudos futuros e uma pergunta. Além disso, ao final da aula, um grupo deveria fazer uma breve exposição sobre uma leitura complementar também indicada pela professora. Cada grupo teve a liberdade de escolher sobre qual tema gostaria de fazer a exposição para que todos pudessem aprofundar seu estudo sobre um assunto que lhes interessasse mais. Tanto a resenha quanto a exposição comporiam a nota final juntamente com duas provas ao longo do semestre.

O desenvolvimento das aulas ocorreu de forma tranquila e a dinâmica pareceu funcionar bem para a docente, para os palestrantes e para os alunos. Também as avaliações no final do semestre indicaram uma opinião bastante positiva dos alunos em relação à disciplina. 0 Quadro 1 apresenta os principais indicadores obtidos. Como foram duas turmas, calculou-se uma média ponderada dos valores de cada sala. A avaliação varia entre 0 e 10.

\section{Quadro 1: Avaliação discente da disciplina}

\begin{tabular}{|l|l|}
\hline \multicolumn{1}{|c|}{ Critério } & \multicolumn{1}{c|}{ Avaliação } \\
\hline Primeira vez que cursa a disciplina? & $100 \%$ dos alunos \\
\hline O professor preparou adequadamente suas aulas? & 9,14 \\
\hline O professor criou interesse pela matéria e estimulou a participação? & 9,03 \\
\hline O professor foi claro e objetivo em suas explicações? & 9,32 \\
\hline O professor utiliza bem o tempo em sala de aula? & 8,97 \\
\hline O programa da disciplina é bem estruturado? & 9,06 \\
\hline As técnicas didáticas utilizadas favoreceram a aprendizagem? & 8,54 \\
\hline Os métodos de avaliação da aprendizagem foram adequados? & 9,23 \\
\hline O conteúdo da disciplina é importante para a formação profissional? & $94 \%$ dos alunos entendem que sim \\
\hline
\end{tabular}

Fonte: Levantamento da Opinião dos Alunos sobre a Qualidade do Curso - FEA/USP.

Com a conclusão da disciplina e os resultados obtidos, que foram bastante positivos, desejou-se aprofundar a compreensão sobre a opinião dos alunos em relação à metodologia de ensino empregada. Especificamente, a questão que norteou a presente pesquisa foi: como os alunos lidam com metodologias ativas de ensino?

\section{APRENDIZAGEM ATIVA}

Em 1987, a American Association for Higher Education (AAHE), em conjunto com a Johnson Foundation (1987), publicou um artigo que afirma que um importante princípio para a boa prática na educação de graduação 
deve ser um ambiente no qual a aprendizagem ativa é encorajada. Também afirma que a aprendizagem não é um esporte de espectador, mas algo cujos estudantes devem "fazer com que a aprendizagem faça parte deles" (SNYDER, 2003).

Bonwell (1991) afirma que os educadores usam o termo "aprendizagem ativa" de forma mais intuitiva do que buscam uma definição comum. Revell e Wainwright (2009) corroboram, dizendo que até recentemente não havia uma definição de "aprendizagem ativa".

O ensino por meio de projetos, assim como o ensino por meio da solução de problemas, são exemplos típicos de metodologias ativas de aprendizagem. Para melhor delinear o conceito, é oportuno lembrar um provérbio chinês que diz: "O que eu ouço, eu esqueço; o que eu vejo, eu lembro; o que eu faço, eu compreendo". Isso foi dito pelo filósofo Confúcio e tem relação direta com aprendizagem ativa. Silberman (1996) modificou tal provérbio para facilitar o entendimento de métodos ativos de aprendizagem, dando a ele a seguinte redação:

- O que eu ouço, eu esqueço;

- O que eu ouço e vejo, eu me lembro;

- O que eu ouço, vejo e pergunto ou discuto, eu começo a compreender;

- O que eu ouço, vejo, discuto e faço, eu aprendo desenvolvendo conhecimento e habilidade;

- O que eu ensino para alguém, eu domino com maestria.

Geralmente, a expressão aprendizagem ativa, que pode ser entendida também como aprendizagem significativa, é usada de forma vaga e imprecisa. Intuitivamente, professores imaginam que toda aprendizagem é inerentemente ativa. Muitos consideram que 0 aluno está sempre ativamente envolvido enquanto assiste a uma aula expositiva. Entretanto, pesquisas da ciência cognitiva sugerem que os alunos devem fazer algo mais do que simplesmente ouvir para ter uma aprendizagem efetiva (MEYERS; JONES, 1993).

Para se envolver ativamente no processo de aprendizagem, o aluno deve ler, escrever, perguntar, discutir ou estar ocupado em resolver problemas e desenvolver projetos. Além disso, o aluno deve realizar tarefas mentais de alto nível, como análise, síntese e avaliação. Nesse sentido, as estratégias que promovem aprendizagem ativa podem ser definidas como sendo atividades que ocupam o aluno em fazer alguma coisa e, ao mesmo tempo, 0 leva a pensar sobre as coisas que está fazendo (BONWELL; EISON, 1991; SILBERMAN, 1996).

É interessante ainda apontar os comentários de Valente (2013, p. 1), que afirma que na "aprendizagem ativa, em oposição à aprendizagem passiva, bancária, baseada na transmissão de informação, 0 aluno assume uma postura mais ativa, na qual ele resolve problemas, desenvolve projetos e, com isto, cria oportunidades para a construção de conhecimento". Ainda segundo o autor, existem inúmeras estratégias para a implementação da aprendizagem ativa, como: a aprendizagem baseada na pesquisa, o uso de jogos ou o problem based learning (PBL).

Assim, aprendizagem ativa ocorre quando o aluno interage com o assunto em estudo - ouvindo, falando, perguntando, discutindo, fazendo e ensinando -, sendo estimulado a construir o conhecimento em vez de recebêlo de forma passiva do professor. Em um ambiente de aprendizagem ativa, o professor atua como orientador, supervisor, facilitador do processo de aprendizagem, e não apenas como fonte única de informação e conhecimento. Por estes motivos, na aprendizagem ativa, a retenção dos conteúdos pelos alunos tende a ser mais efetiva. Um estudo realizado por Freeman et al. (2014) apresentou este fato. A Figura 1 ilustra o resultado da pesquisa, apresentando que a média dos alunos reprovados tende a ser menor em disciplinas que fazem uso de estratégias de aprendizagem ativa do que naquelas que lançam mão apenas de aulas expositivas. 
Figura 1: Comparação das densidades de alunos reprovados

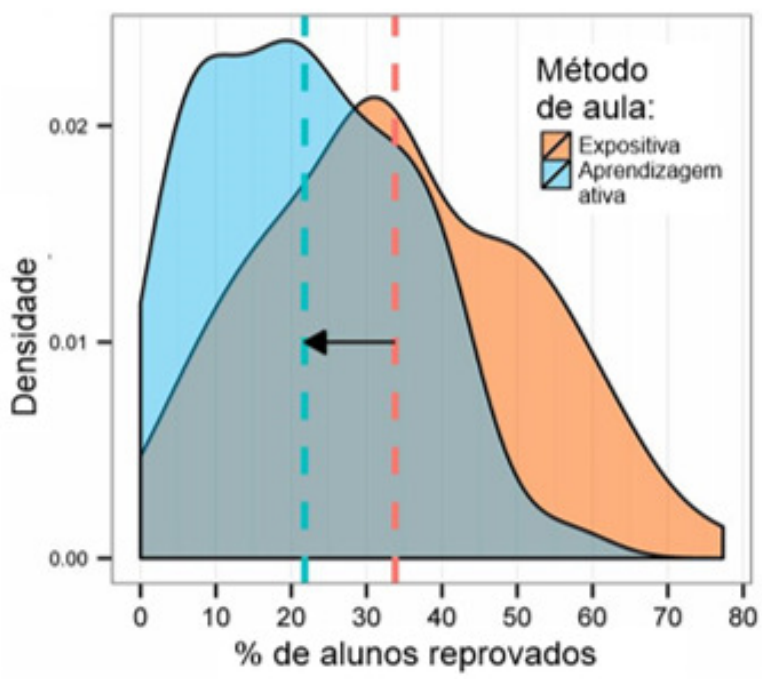

Fonte: Adaptada de Freeman et al. (2014).

Independentemente do método ou da estratégia usada para promover a aprendizagem ativa, é essencial que 0 aluno faça uso de suas funções mentais de pensar, raciocinar, observar, refletir, entender, combinar, dentre outras que, em conjunto, formam a inteligência, segundo a concepção de Pecotche (2011). Em outras palavras, a diferença fundamental que caracteriza um ambiente de aprendizagem ativa é a atitude ativa da inteligência, em contraposição à atitude passiva geralmente associada aos métodos tradicionais de ensino. A relevância das Metodologias Ativas de Ensino-Aprendizagem também está relacionada ao fato de que a aula é atividade secundária (PIAZZI, 2009). De acordo com o autor, a atividade principal é a tarefa. Durante as aulas, o aluno entende, mas apenas quando está desempenhando atividades, resolvendo problemas ou fazendo tarefas é que o aluno aprende. Assim, torna-se importante que o educador evite aulas puramente expositivas.

\section{MÉTODO EMPÍRICO}

Para o desenvolvimento da presente pesquisa, optou-se pela utilização do método do discurso do sujeito coletivo (DSC), cujo objetivo é investigar a fundo os depoimentos de uma coletividade. Trata-se de um método pouco utilizado em administração, mas frequente em trabalhos na área de enfermagem e saúde pública. $O$ foco da presente pesquisa foi a opinião individual de cada aluno, mas também (e mais importante) a reação do grupo à nova abordagem em sala de aula. Por este motivo, o DSC se mostrou um método adequado, uma vez que busca iluminar o campo social pesquisado, procurando entender o que pensa um conjunto específico de pessoas e analisar o significado de algum contexto para tal grupo (LEFEVRE; LEFEVRE, 2010).

O DSC cria um painel de discursos que reflete "o que se pode pensar, numa dada formação sociocultural, num dado grupo ou numa dada coletividade, sobre um determinado assunto" (LEFEVRE; LEFEVRE, 2003, p. 33). Em outras palavras, o Discurso do Sujeito Coletivo pode ser compreendido como um "eu ampliado" e representa a possibilidade de atualização sobre uma opinião compartilhada por um sujeito coletivo a partir da agregação do depoimento de cada elemento individual presente num dado espaço social, num dado momento histórico (LEFEVRE; LEFEVRE, 2006a). Percebe-se, assim, que o objetivo de tal método não é buscar uma generalização, mas gerar opiniões coletivas, mantendo sua substância qualitativa.

Tendo sua fundamentação na Teoria das Representações Sociais (JODELET, 2001) e buscando as ideias compartilhadas dentro de um determinado grupo, a experiência acumulada com o uso da metodologia do DSC mostra um crescente aperfeiçoamento da técnica e de suas inúmeras aplicações (LEFEVRE; LEFEVRE, 2006b). Uma das vantagens do método é o fato de se tratar de uma técnica qualitativa, uma vez que lida com dados qualitativos e não quantificáveis a priori, mas que são quantificados por meio de categorias, muitas vezes com apoio de softwares.

Dados qualitativos, segundo Pereira (2004, p. 21), são a "representação simbólica atribuída a manifestações de um evento qualitativo", no caso, a opinião dos alunos sobre o método de ensino. É importante 
também ressaltar que a mensuração de eventos qualitativos se dá por meio da mensuração não do próprio objeto em si (a opinião dos alunos), mas de seus predicados, sendo o dado qualitativo "uma estratégia de mensuração" (PEREIRA, 2004, p. 30). Nesse sentido, o "desafio a que o DSC busca responder é o da auto expressão do pensamento ou opinião coletiva, respeitando-se a dupla condição qualitativa e quantitativa destes como objeto" (LEFEVRE; LEFEVRE, 2006b, p. 518).

Também é possível afirmar que a riqueza do método reside no fato de que, diferente de outros métodos qualitativos, o DSC busca a construção de uma realidade a partir da representação social. Ou seja, o coletivo é reconstituído a partir da opinião de um conjunto de discursos na primeira pessoa do singular. Nas palavras de seus idealizadores,

\begin{abstract}
Ora, aparentemente tal sujeito coletivo não pode falar porque, se permanecermos positivisticamente atrelados às possibilidades oferecidas pela língua (a portuguesa e muitas outras), só disporemos de um modo precário para acessar, diretamente, o sujeito coletivo, que é o pronome "nós" da primeira pessoa do plural, não existindo a alternativa do "eu coletivo".

Ora, um sujeito coletivo, como o entendemos no Discurso do Sujeito Coletivo, é muito mais do que um "nós", que expressa apenas um tipo muito particular de sujeito coletivo que fala [Aquele resultante de um acordo explícito de indivíduos, presente em frases do tipo: "nós, metalúrgicos, reunidos em assembléia, decidimos paralisar..."]; e, também, menos, já que um único indivíduo também pode ser um sujeito coletivo.

Nas pesquisas de opinião tradicionais, o sujeito da opinião (aquele que fala: "na minha opinião..."; ou "eu acho que..."; ou "eu acredito que...") é, quase sempre, um indivíduo ou, no máximo, um "nós". Assim, um sujeito coletivo da opinião não encontraria formas diretas de se expressar e, "portanto", passaria a não existir, ou, mais precisamente, a não ser visto como um falante, sendo apenas passível de ser indiretamente resgatado como um "eles" de quem se fala ou como um sujeito artificial não-lingüístico do tipo "30\% dos usuários do posto de saúde acham que..." (LEFEVRE; LEFEVRE, 2006b, p. 518).
\end{abstract}

Além disso, outra vantagem do método DSC é o fato de que nele "fica preservada a natureza essencialmente discursiva e qualitativa da opinião ou representação e, inseparável dela, a dimensão quantitativa, associada à representatividade e generalização dos resultados" (LEFEVRE; LEFEVRE, 2010, p. 16).

Como técnica, o DSC consiste em uma série de operações sobre os depoimentos individuais ou outros tipos de dados secundários sobre o objeto de pesquisa. A partir da matéria-prima coletada, buscam-se construtos confeccionados com estratos literais. Segundo Lefevre e Lefevre (2010, p. 21), "os membros de uma formação social determinada costumam falar (aproximadamente) a mesma língua (no caso da não existência de formas diletais), mas não compartilham necessariamente as mesmas ideias". 0 intuito do método é buscar as opiniões convergentes, os temas semelhantes nos discursos individuais para, a partir dessas ideias, construir um discurso que represente a coletividade. Nesse sentido, é interessante também destacar a opinião dos autores, para quem a representação social nada mais é do que o social vivido individualmente. Ou seja, por meio da combinação dos sujeitos individuais é possível se chegar ao sujeito coletivo.

Contudo, como qualquer método de pesquisa, é importante haver consciência sobre seus riscos e aspectos éticos. Nesse sentido, Lefevre e Lefevre (2006a, p. 3) apontam que:

Para usar a terminologia de Peirce [1975] podemos dizer que o discurso deste sujeito coletivo (que, apesar de ser coletivo, permanece um sujeito) é um signo representamem dos diferentes depoimentos com que é elaborado. Assim, pois, como um advogado ou deputado, implica um sujeito que representa ou fala pelos seus representados.

Então, todos os sujeitos individuais com os quais o sujeito coletivo é composto precisam estar representados neste sujeito coletivo; o que equivale dizer que o sujeito coletivo não pode estar, de nenhum modo, "traindo" nenhum dos sujeitos individuais dos quais é composto: não pode ser posto na "boca do coletivo" nada do que não esteja "na boca dos indivíduos" que compõe este coletivo; por outro lado, de um ponto de vista quantitativo, os diferentes matizes da mesma idéia devem ser incorporados no sujeito coletivo.

\title{
3.1 Respondentes
}

Como o objetivo do presente estudo é aprofundar a compreensão sobre a avaliação coletiva dos alunos de administração sobre um determinado método de ensino empregado, os atores sociais em questão devem ser 
os próprios alunos que cursaram a disciplina em que foi empregada a metodologia de ensino-aprendizagem ativa. Para tanto, foi elaborado um instrumento de coleta com 10 questões abertas.

Para se obter um volume maior de respondentes, ampliando a compreensão da coletividade, optou-se pela coleta dos depoimentos por meio de um questionário estruturado e não por meio de entrevistas. Deve-se ressaltar que o DSC prevê que os discursos individuais sejam coletados isoladamente, de modo que uma entrevista coletiva ou grupo focal não seriam adequados. A coleta ocorreu em junho de 2016, durante uma disciplina do curso de administração. Dos 70 alunos que haviam cursado e avaliado formalmente a disciplina em análise, 52 participaram do presente estudo. Para estimular a honestidade dos respondentes, as folhas de resposta foram devolvidas de forma anônima.

\title{
3.2 Instrumento de coleta
}

A proposta do Discurso do Sujeito Coletivo com base, sobretudo, nos pressupostos da Teoria das Representações Sociais, é elencar e articular uma série de operações sobre a matéria-prima de depoimentos coletados em pesquisas empíricas de opinião por meio de questões abertas (LEFEVRE; LEFEVRE, 2006b). Por este motivo, o desenvolvimento do instrumento de coleta levou em conta que atribuir sentido como ato social envolve, entre outras coisas, perguntas abertas sobre o que o indivíduo pensa sobre determinada situação, qual sua opinião sobre ela, como vê, vive, define, avalia e se posiciona perante o objeto em análise (LEFEVRE; LEFEVRE, 2010). Cada questão foi formulada de forma a dar liberdade para o indivíduo manifestar seu ponto de vista e sentimentos sobre aspectos diversos da metodologia de ensino em análise. Pediu-se para que o respondente expressasse sua opinião, suas considerações, críticas e anseios com relação à condução da disciplina de marketing. Foram duas questões sobre o desenvolvimento dos conteúdos durante a disciplina, duas questões com relação à forma de avaliação, quatro questões sobre o interesse e nível de aprendizagem dos alunos e duas questões para críticas e sugestões gerais. Juntamente com o questionário, foram entregues folhas de papel para resposta, de modo que os alunos não tivessem limitação de espaço para suas respostas.

\subsection{Análise dos dados}

A construção do discurso coletivo deve seguir alguns passos e diversos cuidados devem ser observados. Por exemplo, Lefevre e Lefevre (2010, p. 45) destacam que em uma

\begin{abstract}
...pesquisa qualitativa o pesquisador tem sempre a segurança de que, se ao menos um entrevistado explicita uma dada ideia, essa está presente no campo pesquisado. Em contrapartida, deve cercar-se de alguns cuidados para dizer que uma ideia não está presente, pois poderia não ter selecionado adequadamente seus entrevistados e essa ideia, por isso, não surgiu.
\end{abstract}

$\mathrm{Na}$ tentativa de se minimizar esse risco, tentou-se entrevistar o maior número de alunos da população de interesse, alcançando-se $74 \%$ dela. Ainda assim, "Como nessas pesquisas as pessoas interessam menos que seus discursos, a quantidade não é uma variável crítica, sendo a variabilidade muito mais crítica" (LEFEVRE; LEFEVRE, 2000, p. 35).

Para a análise que se seguiu, cada questionário foi analisado e as expressões-chave (ECH) foram destacadas. Uma ECH é um pedaço ou trecho (contínuo ou descontínuo) do depoimento individual que revelam a essência do conteúdo. A partir das ECH, buscou-se definir as ideias centrais (IC), nome ou expressão linguística que sintetiza as ECH. Outros métodos qualitativos, como a grounded theory, por exemplo, chamam essa etapa de codificação. Da mesma forma, as IC são utilizadas para se buscar as semelhanças e as convergências ou divergências nos discursos individuais, criando-se categorias. A partir de tais categorias, o discurso-síntese, 0 efetivo discurso do sujeito coletivo, é construído. Destaca-se, contudo, que embora o DSC seja construído a partir dos discursos individuais, assim como em outros métodos qualitativos, a figura do pesquisador como instância organizadora e produtora dessa fala do social não pode ser ignorada. Daí a importância de se considerar algumas questões durante 0 ato de juntar peças: a coerência na criação de IC e categorias, a busca pelo posicionamento próprio de cada indivíduo, o cuidado com as diferenças e as complementaridades de cada "peça", e o cuidado para não se criar uma "naturalidade artificial" (LEFEVRE; LEFEVRE, 2000). Os autores destacam ainda que, 
embora as IC e as categorias possam ser quantificadas, quando o sujeito coletivo é de natureza qualitativa não faz sentido que ele seja matematizado, atribuindo-se porcentagens a cada trecho ou ocorrências.

A análise dos dados foi desenvolvida com o apoio do software DSCsoft, versão 1.1.0.0, especificamente desenvolvido para a utilização do método do Discurso do Sujeito Coletivo. Embora alguns autores apresentem ressalvas quanto ao uso de programas e computadores na análise de dados qualitativos (WEITZMAN; MILES, 1995; MANGABEIRA, 1996), há diversos trabalhos que defendem seu uso (RICHARDS, 2002; BRINGER; JOHNSTON; BRACKENRIDGE, 2004; BANDEIRA-DE-MELLO, 2006; MCKENNY; SHORT; PAYNE, 2013). Pode ser citado o texto de Sinkovics e Alfoldi (2012), em que os autores encorajam os pesquisadores qualitativos a usar programas do tipo CAQDAS (Computer-Assisted Qualitative Data Analysis Software) para organizar os documentos. Os autores alertam que um CAQDAS não resolve todos os problemas, mas auxilia a documentar 0 rigor do processo analítico. Também afirmam que o programa pode ser utilizado para potencializar a sistematização, a reflexão e a efetividade operacional da pesquisa qualitativa. Esse distanciamento dos dados, como denomina Gilbert (2002), é saudável e não inviabiliza a necessária proximidade aos dados em pesquisas qualitativas.

\section{ANÁLISE E DISCUSSÃO DOS RESULTADOS}

Antes de se buscar a construção do discurso coletivo, é interessante apresentar alguns aspectos gerais sobre os 52 depoimentos coletados. De modo geral, ambas as turmas consideraram a disciplina boa e interessante, com temas relevantes ("As aulas foram muito claras, com conteúdo relevante e aplicável"). Muitos alunos passaram a se interessar por novos temas que ainda não dominavam ou que conheciam superficialmente ("Passei a ter interesse em Sustentabilidade, Ética, Consumo Colaborativo e Vulnerabilidade do Consumidor, (...) extremamente interessantes as abordagens acadêmicas sobre os assuntos"). Também consideraram os instrumentos de avaliação justos e adequados, minimizando a necessidade de se decorar conceitos desnecessariamente ou de forma artificial ("A avaliação foi justa e evitou "decorebas", aprofundando discussões"). O formato com palestras dividiu os alunos. Alguns acharam que a disciplina ficou dinâmica e interessante ("Acredito que um profissional de cada área ministrando a aula acaba sendo melhor do que um único profissional ministrando "superficialmente" todos os conceitos"); já outros alegaram que sentiram falta de aulas teóricas ("Senti falta de aulas mais teóricas") e aulas ministradas pela própria professora (Foi boa e interessante, mas senti falta de aulas ministradas pela professora").

Em sua maioria, os alunos sentiram falta de uma linha condutora, de mais clareza na relação entre os temas, sentindo que a disciplina não teve uma integração ("Poderia ter tido uma estruturação maior no sentido de prover uma linearidade, fazendo com que os temas se conectassem melhor"). Ainda assim, houve aprendizagem e eles não se sentiram perdidos ao longo das aulas ("Achei a disciplina muito boa para a formação do profissional, trazendo conteúdo diversificado e que realmente acrescenta ao profissional em Marketing").

Além das transcrições já apresentadas anteriormente, o Quadro 2 apresenta as principais expressõeschave, as ideias centrais e as categorias que foram criadas ao longo da análise dos dados.

Quadro 2: Preparação dos Discursos Individuais

\begin{tabular}{|c|c|c|}
\hline Expressão-chave (ECH) & Ideia Central (IC) & Categoria \\
\hline Não senti que as palestras agregaram conhecimento. Preferia aulas expositivas. & $\begin{array}{l}\text { Aquisição de } \\
\text { conhecimento }\end{array}$ & Aq- \\
\hline $\begin{array}{l}\text { Acredito que a disciplina não acrescentou muito em termos de conceitos e aplicações } \\
\text { de comportamento do consumidor. }\end{array}$ & $\begin{array}{l}\text { Aquisição } \\
\text { conhecimento }\end{array}$ & Aq- \\
\hline $\begin{array}{l}\text { Achei a disciplina muito boa para a formação do profissional, trazendo conteúdo } \\
\text { diversificado e que realmente acrescenta ao profissional. }\end{array}$ & $\begin{array}{l}\text { Aquisição } \\
\text { conhecimento }\end{array}$ & $\mathrm{Aq}^{+}$ \\
\hline Achei que a matéria foi um pouco vazia em conteúdo. & $\begin{array}{l}\text { Aquisição } \\
\text { conhecimento }\end{array}$ & Aq- \\
\hline $\begin{array}{l}\text { Metodologia utilizada fugiu dos padrões normais de aula e, assim, proporcionou um } \\
\text { aprendizado muito maior. }\end{array}$ & $\begin{array}{l}\text { Aquisição } \\
\text { conhecimento }\end{array}$ & $\mathrm{Aq}+$ \\
\hline $\begin{array}{l}\text { Houve aprendizado, pois os temas trazidos foram abordados de forma mais } \\
\text { aprofundada e clara. }\end{array}$ & $\begin{array}{l}\text { Aquisição } \\
\text { conhecimento }\end{array}$ & $\mathrm{Aq}+$ \\
\hline
\end{tabular}




\begin{tabular}{|c|c|c|}
\hline Expressão-chave (ECH) & Ideia Central (IC) & Categoria \\
\hline $\begin{array}{l}\text { O fato de terem sido apresentados [os temas] por palestrantes e, assim, muitos } \\
\text { exemplos reais, ajuda a criar o interesse e estimular o maior aprendizado e fixação } \\
\text { do conhecimento. Meses depois, ainda lembro de muitas das palestras, mas não } \\
\text { lembro tão bem das aulas. }\end{array}$ & $\begin{array}{l}\text { Aquisição de } \\
\text { conhecimento }\end{array}$ & $\mathrm{Aq}+$ \\
\hline $\begin{array}{l}\text { A professora poderia separar } 10 \text { minutos de cada aula para apresentar rapidamente } \\
\text { o conceito e melhorar o entendimento. }\end{array}$ & $\begin{array}{l}\text { Aquisição } \\
\text { conhecimento }\end{array}$ & AqProf \\
\hline $\begin{array}{l}\text { Acredito que a disciplina trouxe conteúdos muito interessantes e foi positivo ter os } \\
\text { tópicos abordados por pessoas com profundo conhecimento e vivência deles. }\end{array}$ & $\begin{array}{l}\text { Avaliação } \\
\text { disciplina } \\
\text { (palestrantes) }\end{array}$ & $\mathrm{Av}+$ \\
\hline $\begin{array}{l}\text { Achei a forma que a disciplina foi dada com palestras de especialistas muito } \\
\text { interessante, trazendo conteúdo novo e apresentando de uma forma inovadora que } \\
\text { chama muito a atenção. }\end{array}$ & $\begin{array}{l}\text { Avaliação } \\
\text { disciplina } \\
\text { (palestrantes) }\end{array}$ & $\mathrm{Av}+$ \\
\hline Foi boa e interessante, mas senti falta de aulas ministradas pela professora. & $\begin{array}{l}\text { Avaliação } \\
\text { disciplina } \\
\text { (palestrantes) }\end{array}$ & AvProf \\
\hline Muito positiva. A disciplina foi muito dinâmica e a professora muito didática. & $\begin{array}{l}\text { Avaliação da } \\
\text { disciplina (qualidade) }\end{array}$ & $\mathrm{Av}+$ \\
\hline As aulas foram muito claras, com conteúdo relevante e aplicável. & $\begin{array}{l}\text { Avaliação da } \\
\text { disciplina (qualidade) }\end{array}$ & $\mathrm{Av}+$ \\
\hline $\begin{array}{l}\text { Não são aulas somente com teorias de séculos passados, mas ilustradas com } \\
\text { exemplos reais e atuais, o que valorizo muito. }\end{array}$ & $\begin{array}{l}\text { Avaliação da } \\
\text { disciplina (qualidade) }\end{array}$ & $A v+$ \\
\hline A avaliação foi justa e evitou "decorebas", aprofundando discussões. & $\begin{array}{l}\text { Instrumento de } \\
\text { avaliação }\end{array}$ & $\mathrm{Prt}$ \\
\hline $\begin{array}{l}\text { Poderia ter tido uma estruturação maior no sentido de prover uma linearidade, } \\
\text { fazendo com que os temas se conectassem melhor. }\end{array}$ & $\begin{array}{l}\text { Planejamento e } \\
\text { estrutura da disciplina }\end{array}$ & Plan- \\
\hline Disciplina bem pensada e organizada. & $\begin{array}{l}\text { Planejamento } \mathrm{e} \\
\text { estrutura da disciplina }\end{array}$ & Plan+ \\
\hline $\begin{array}{l}\text { Em geral abordou temas interessantes, porém, ao meu ver, faltou integração entre } \\
\text { as aulas dentro da matéria. }\end{array}$ & $\begin{array}{l}\text { Planejamento } \mathrm{e} \\
\text { estrutura da disciplina }\end{array}$ & Plan- \\
\hline $\begin{array}{l}\text { Acredito que um profissional de cada área ministrando a aula acaba sendo melhor } \\
\text { do que um único profissional ministrando "superficialmente" todos os conceitos. }\end{array}$ & $\begin{array}{l}\text { Planejamento e } \\
\text { estrutura da disciplina }\end{array}$ & Plant \\
\hline $\begin{array}{l}\text { Gostei bastante da disciplina pela diversidade de conhecimentos propostos, pelo } \\
\text { formato de transposição do conteúdo (textos para leitura em casa e palestras } \\
\text { expositivas). }\end{array}$ & $\begin{array}{l}\text { Planejamento e } \\
\text { estrutura da disciplina }\end{array}$ & Plant \\
\hline Senti falta de aulas mais teóricas. & $\begin{array}{ll}\text { Planejamento } & \mathrm{e} \\
\text { estrutura da disciplina }\end{array}$ & Plan- \\
\hline $\begin{array}{l}\text { A disciplina abordou temas relevantes e sem muita profundidade, isso é bom, porque } \\
\text { me deixou livre para pesquisar com mais profundidade os assuntos de meu interesse. }\end{array}$ & $\begin{array}{l}\begin{array}{l}\text { Profundidade dos } \\
\text { temas }\end{array} \\
\end{array}$ & Proft \\
\hline $\begin{array}{l}\text { Interessante, devido à amplitude de temas abordados, mas poderia ter se } \\
\text { aprofundado mais em alguns. }\end{array}$ & $\begin{array}{l}\text { Profundidade dos } \\
\text { temas }\end{array}$ & Prof- \\
\hline $\begin{array}{l}\text { De forma geral, a disciplina foi boa. Era um atrativo para os alunos ter palestra toda } \\
\text { aula, embora um artigo científico por aula pudesse ser uma leitura muito extensa em } \\
\text { algumas semanas. }\end{array}$ & Tempo de estudo & Est+ \\
\hline
\end{tabular}

Fonte: Dados da pesquisa.

A partir dos trechos anteriores $(E C H)$, pôde ser criado o discurso do sujeito coletivo:

Achei a forma que a disciplina foi dada com palestras de especialistas muito interessantes, trazendo conteúdo novo e apresentando de uma forma inovadora que chama muito a atenção. Não são aulas somente com teorias de séculos passados, mas ilustradas com exemplos reais e atuais, o que valorizo muito. [A] Metodologia utilizada fugiu dos padrões normais de aula e, assim, proporcionou um aprendizado muito maior. 0 fato de terem sido apresentados [os temas] por palestrantes e, assim, muitos exemplos reais, ajuda a criar o interesse e estimular o maior aprendizado e fixação do conhecimento. Meses depois, ainda lembro de muitas das palestras, mas não lembro tão bem das aulas. Acredito que a disciplina trouxe conteúdos muito interessantes e foi positivo ter os tópicos abordados por pessoas com profundo conhecimento 
e vivência deles. A disciplina abordou temas relevantes e sem muita profundidade, isso é bom, porque me deixou livre para pesquisar com mais profundidade os assuntos de meu interesse (dentro dos diversos tópicos apresentados). A avaliação foi justa e evitou "decorebas", aprofundando discussões. De forma geral, a disciplina foi boa. Era um atrativo para os alunos ter palestra toda aula, embora um artigo científico por aula pudesse ser uma leitura muito extensa em algumas semanas. [Contudo] Senti falta de aulas mais teóricas. Foi boa e interessante, mas senti falta de aulas ministradas pela professora. A professora poderia separar 10 minutos de cada aula para apresentar rapidamente o conceito e melhorar 0 entendimento. Poderia ter tido uma estruturação maior no sentido de prover uma linearidade, fazendo com que os temas se conectassem melhor.

Ainda com base na matéria-prima coletada e nos resultados do DSC, a partir da técnica de comparação constante, foi possível buscar as relações menos factuais (próximas ao discurso efetivo) entre as ideias centrais, criando-se redes entre elas e, a partir destas, gerar novos conceitos (códigos) mais abstratos. Em uma análise hermenêutica (interpretativista), buscou-se aprofundar o entendimento do que foi dito pelos entrevistados, procurando o que estava implícito nas palavras. Deve-se ressaltar que se trata de uma análise qualitativa e exploratória. Seu intuito é iluminar questões para futuro aprofundamento. Assim, chegou-se à construção de dois construtos que são apresentados a seguir, com trechos extraídos dos depoimentos dos alunos (quotations).

1. Os depoimentos apresentaram diferentes níveis de independência. Independência no sentido de autonomia para se buscar respostas por conta própria; de não se prender exclusivamente ao que o professor fala e sugere que se leia e faça. Godoy (1989) usa o termo "independência intelectual" para se referir a este construto. A Figura 2 ilustra as evidências extraídas do texto:

Figura 2: Independência dos alunos

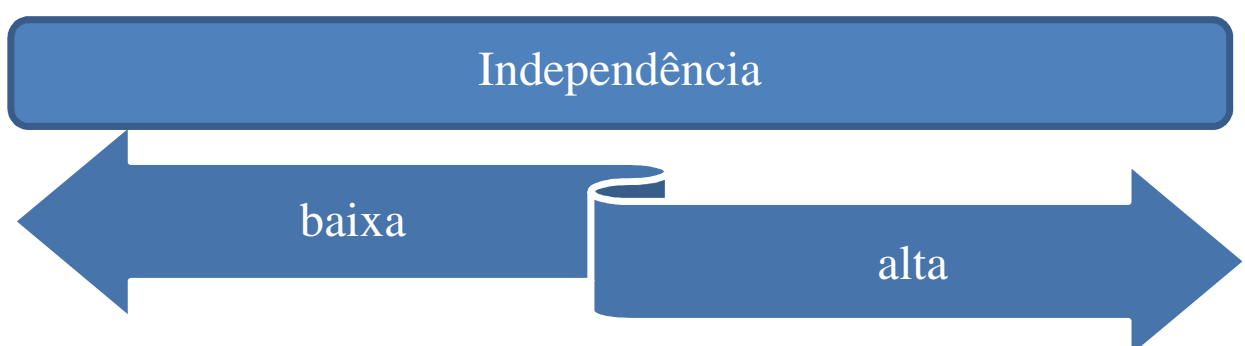

\begin{tabular}{|l|l|}
\hline $\begin{array}{l}\text { Acredito que a disciplina não acrescentou muito em termos } \\
\text { de conceitos e aplicações de marketing e comportamento do } \\
\text { consumidor. }\end{array}$ & $\begin{array}{l}\text { Metodologia utilizada fugiu dos padrões normais de aula } \\
\text { e, assim, proporcionou um aprendizado muito maior. }\end{array}$ \\
\hline $\begin{array}{l}\text { A disciplina é interessante, porém não agrega tantos } \\
\text { conhecimentos como o modelo de aula tradicional. }\end{array}$ & $\begin{array}{l}\text { Houve aprendizado, pois os temas trazidos foram } \\
\text { abordados de forma mais aprofundada e clara. }\end{array}$ \\
\hline Achei que a matéria foi um pouco vazia em conteúdo. & $\begin{array}{l}\text { Gostei bastante da disciplina pela diversidade de } \\
\text { conhecimentos propostos, pelo formato de transposição } \\
\text { do conteúdo (textos para leitura em casa e palestras } \\
\text { expositivas). }\end{array}$ \\
\hline $\begin{array}{l}\text { Foi boa e interessante, mas senti falta de aulas ministradas } \\
\text { pela professora }\end{array}$ & $\begin{array}{l}\text { A disciplina abordou temas relevantes e sem muita } \\
\text { profundidade, isso é bom, porque me deixou livre para } \\
\text { pesquisar com mais profundidade os assuntos de meu } \\
\text { interesse (dentro dos diversos tópicos apresentados). }\end{array}$ \\
\hline
\end{tabular}

Fonte: Elaborada pelos autores.

2. Os relatos individuais também evidenciaram diferentes níveis de capacidade de abstração, ou seja, a capacidade de compreensão de um dado conceito teórico e sua aplicação prática por profissionais de mercado. Este construto é apresentado pela Figura 3. 
Figura 3: Capacidade de abstração dos alunos

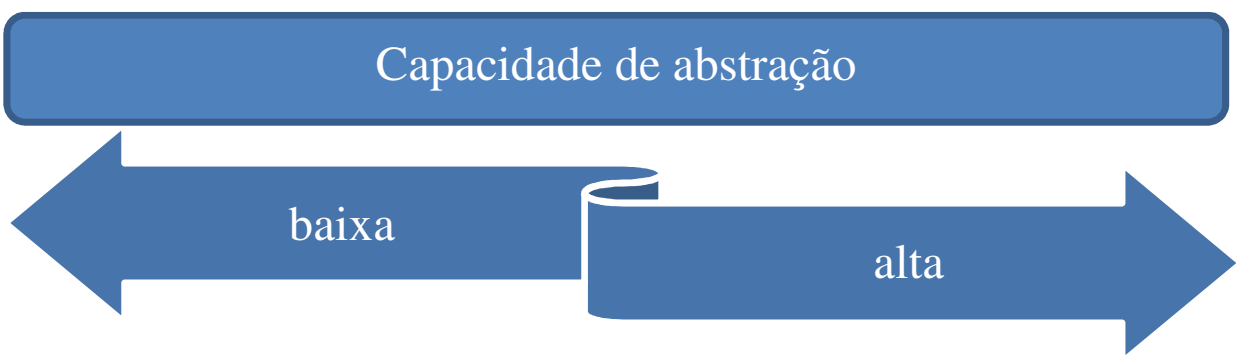

\begin{tabular}{|l|l|}
\hline $\begin{array}{l}\text { Não senti que as palestras agregaram conhecimento. Preferia } \\
\text { aulas expositivas. }\end{array}$ & $\begin{array}{l}\text { Achei a disciplina muito boa para a formação do } \\
\text { profissional, trazendo conteúdo diversificado e que } \\
\text { realmente acrescenta ao profissional em Marketing. }\end{array}$ \\
\hline Achei que a matéria foi um pouco vazia em conteúdo. & $\begin{array}{l}\text { As aulas foram muito claras, com conteúdo relevante e } \\
\text { aplicável. }\end{array}$ \\
\hline Me sinto mais confortável com aulas dadas pela professora. & $\begin{array}{l}\text { Acredito que a disciplina trouxe conteúdos muito } \\
\text { interessantes e foi positivo ter os tópicos abordados por } \\
\text { pessoas com profundo conhecimento e vivência deles. }\end{array}$ \\
\hline $\begin{array}{l}\text { Acho que a teoria deve ser primeiro explicada para que depois } \\
\text { seja apresentada uma palestra. }\end{array}$ & $\begin{array}{l}\text { Achei a forma que a disciplina foi dada com palestras de } \\
\text { especialistas muito interessante, trazendo conteúdo novo } \\
\text { eapresentando de uma forma inovadora que chama muito } \\
\text { a atenção. }\end{array}$ \\
\hline
\end{tabular}

Fonte: Elaborada pelos autores.

Embora seja uma proposta qualitativa, sem a pretensão de se generalizar o achado, os trechos destacados parecem estar relacionados a um fenômeno maior, que integra toda a discussão sobre como os alunos lidam com novas metodologias: a maturidade dos alunos. Destaca-se que as evidências apresentam limitações, pois foram coletadas de uma única turma, de um único curso, com relação a uma única disciplina. Além disso, são alunos que, de modo geral, não foram aculturados quanto a novas metodologias. Por este motivo, é natural que muito se sintam mais confortáveis com o formato tradicional de aula expositiva, com um professor apresentando e analisando conceitos e teorias.

Ainda assim, com base nos dois construtos (independência e capacidade de abstração), propõe-se a criação de uma tipologia dos alunos a partir de seu cruzamento. Uma tipologia inicial, a ser aprofundada em novos estudos, baseada no nível de maturidade dos alunos. A Figura 4 ilustra a proposta com 4 perfis de alunos:

Figura 4: Maturidade dos alunos

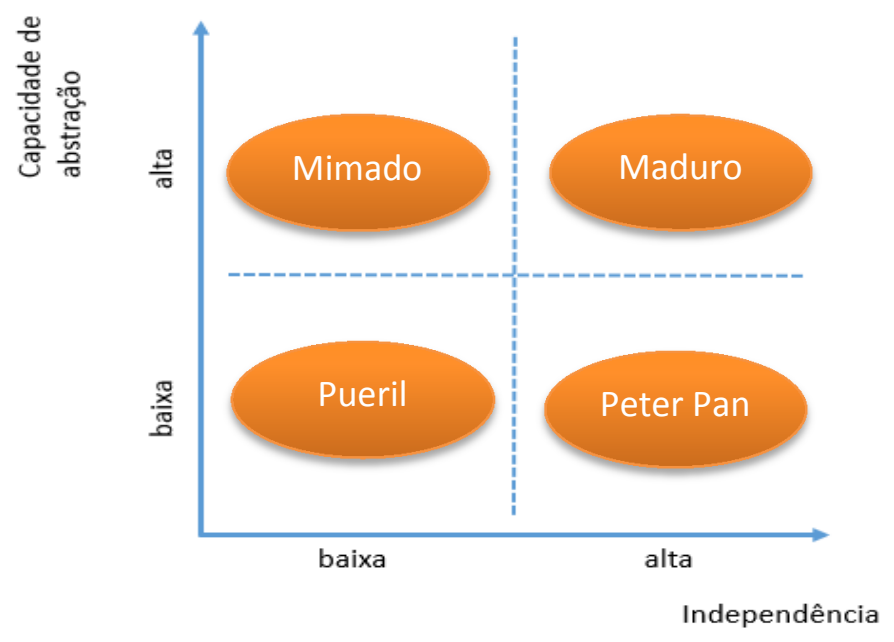

Fonte: Elaborada pelos autores.

Revista Alcance - Eletrônica - vol. 24 - n. 3 - jul./set. 2017 
Os perfis criados distinguem os alunos quantos aos construtos definidos, mas também evidenciam diferenças nos estilos de aprendizagem. De forma sucinta, os perfis podem ser explicados e ilustrados como:

- Mimado: é um aluno que apresenta alta capacidade de compreensão e abstração, mas que permanece dependente de direcionamento. Seja por preguiça, insegurança ou medo, esse perfil de aluno tende a preferir atividades que não se limitem à mera exposição teórica, mas não abrem mão de um acompanhamento próximo do professor ("Senti falta de maior presença e conhecimento da professora. [...] Os textos eram muito chatos e grandes").

- Pueril: trata-se de um aluno que ainda se sente perdido no meio acadêmico. Ele se agarra ao padrão tradicional de aula, com exposição de teoria e exercícios simples de fixação, todos com elevado grau de ingerência do professor ("Achei que a matéria foi um pouco vazia em conteúdo. Preferia aulas expositivas").

- Peter Pan: com alusão ao personagem da literatura, esse perfil de aluno se sente bastante independente, assumindo para si a responsabilidade pela leitura, estudo e pesquisa. Contudo, apresenta dificuldade de abstrair o conteúdo dos livros e vislumbrar a aplicação prática dos conceitos. Sente dificuldade em resolver estudos de caso, por exemplo, ou de aproveitar melhor palestras e seminários de profissionais de mercado ("Conhecemos muitas pessoas, mas muitas vezes as aulas eram desconectadas das palestras e não havia fixação do conteúdo. Algumas aulas faziam sentido dentro do contexto de Marketing, porém teve algumas que eu não consegui ver aplicabilidade ou objetividade no assunto").

- Maduro: é um perfil de aluno que se aproxima do autodidata. Ele sabe como se organizar, pesquisar e estudar, bem como sente facilidade em enxergar os elos entre a teoria e a prática ("A disciplina abordou temas relevantes e sem muita profundidade, isso é bom, porque me deixou livre para pesquisar com mais profundidade os assuntos de meu interesse").

\section{CONSIDERAÇÕES FINAIS}

Esta pesquisa buscou aprofundar a compreensão sobre a opinião dos alunos quanto à metodologia de ensino empregada, diferenciando 4 formas de 0 aluno lidar com ela e mostrando que mudanças mais drásticas na condução das aulas (ainda que possa ser um anseio dos alunos) podem causar dissonâncias e algum desconforto entre os alunos. $O$ coletivo não é absolutamente homogêneo; há diferentes vivências, repertórios e estilos de aprendizagem, de modo que qualquer mudança precisa ser progressiva e respeitar a variedade.

Observa-se que os alunos desejam uma revisão da metodologia de ensino utilizada em sala de aula. Novas técnicas, novas dinâmicas e mais autonomia é algo visto como positivo por muitos. Contudo, a sala de aula não é homogênea. De acordo com a análise desenvolvida, foi possivel identificar 4 perfis de alunos. Considerando que há diferentes perfis e que existem diferentes estilos de aprendizagem, os docentes podem construir suas disciplinas com diferentes metodologias. Ainda que seja um achado exploratório e que merece aprofundamento com base em novos estudos, inclusive descritivos, trata-se de um insight relevante, pois reforça a quebra de paradigma e a necessidade de os docentes repensarem seu papel e estratégias em sala.

Embora as técnicas ativas sejam comprovadamente mais efetivas, com resultados superiores às metodologias tradicionais, recomenda-se como necessário respeitar o tempo do aluno para se potencializar 0 aprendizado coletivo. Na disciplina em questão, houve uma mudança radical e o padrão das aulas seguiu basicamente um único caminho. Isso causou ruído e desconforto para alguns alunos, que não aproveitaram ao máximo os conteúdos que foram apresentados pelos profissionais de mercado.

Retomando os perfis identificados, é interessante que o professor mantenha em mente que deve oferecer atividades que atendam aos perfis mais independentes, estimulando a responsabilidade, a pesquisa e a discussão em grupo, mas também desenvolva situações em que sua presença fique evidente. Além disso, recomenda-se combinar atividades mais teóricas, focadas em aulas expositivas sobre conceitos e modelos, com atividades de aplicação, que exijam do aluno um esforço no sentido de abstração e resolução de problemas. Discussão com profissionais de mercado e estudos de caso são possibilidades a serem utilizadas. 


\section{REFERÊNCIAS}

BANDEIRA-DE-MELLO, R. Softwares em pesquisa qualitativa. In: GODOI, C; BANDEIRA-DE-MELLO, R.; SILVA, A. (Org.). Pesquisa qualitativa em estudos organizacionais: paradigmas, estratégias e métodos. São Paulo: Saraiva, 2006, p. 429-460.

BONWELL, C. C.; EISON, J. A. Active Learning: Creating Excitement in the Classroom. ERIC Digest. Higher Education $\quad$ Reports, $1991 . \quad$ Disponivel em: $<$ http://www.oid.ucla.edu/about/units/tatp/old/lounge/pedagogy/downloads/active-learning-eric.pdf $>$. Acesso em: 05 mar. 2016.

BORDENAVE, J. D.; PEREIRA, A. M. Estratégias de ensino-aprendizagem. Petrópolis: Vozes, 1995.

BRINGER, J. D.; JOHNSTON, L. H.; BRACKENRIDGE, C. H. Maximizing transparency in a doctoral thesis: The complexities of writing about the use of QSR ${ }^{*}$ NVIVO within a grounded theory study. Qualitative research, v. 4, n. 2, p. 247-265, 2004.

FERRARI, M. Paulo Freire, 0 mentor da educação para a consciência. Disponível em: <http://ambientedopedagogo.blogspot.com.br/p/paulo-freire.html>. Acesso em: 02 jun. 2016.

FREEMAN, S.; EDDY, S. L.; MCDONOUGH, M.; SMITH, M. K.; OKOROAFOR, N.; JORDT, H.; WENDEROTH, M. $P$. Active learning increases student performance in science, engineering, and mathematics. Proceedings of the National Academy of Sciences, v. 111, n. 23, p. 8410-8415, 2014.

GILBERT, L. S. Going the distance: 'closeness' in qualitative data analysis software. International journal of social research methodology, v. 5, n. 3, p. 215-228, 2002.

GODOY, A. S. Revendo a aula expositiva. In: MOREIRA, D. A. Didática do ensino superior: técnicas e tendências. São Paulo: Pioneira, 1997, p. 75-82.

JODELET, D. Representações sociais: um domínio em expansão. In: JODELET, D. (Org.). As representações sociais. Rio de Janeiro: EDUERJ, 2001. p. 17-44.

LEFEVRE, F. Pesquisa de representação social: um enfoque qualiquantitativo: a metodologia do Discurso do Sujeito Coletivo. Brasília: Líber Livro Editora, 2010.

LEFEVRE, F.; LEFEVRE, A. M. C. Discurso do sujeito coletivo: um novo enfoque em pesquisa qualitativa (desdobramentos). Caxias do Sul: EDUCS, 2003.

LEFEVRE, F.; LEFEVRE, A. M. C. 0 discurso do sujeito coletivo como expressão narrativa da quantidade. 2006a. Disponível em: <http://www.ipdsc.com.br>. Acesso em: 19 mai. 2016.

LEFEVRE, F.; LEFEVRE, A. M. C. O sujeito coletivo que fala. Interface - Comunicação, Saúde, Educação, v. 10 , n. 20, p. 517-524, 2006b.

LEFEVRE, F.; LEFEVRE, A. M. C. Os novos instrumentos no contexto da pesquisa qualitativa. In: LEFEVRE, F.; LEFEVRE, A. M. C.; TEIXEIRA, J. J. V. (Org.). 0 discurso do sujeito coletivo: uma nova abordagem metodológica em pesquisa qualitativa. Caxias do Sul: EDUCS, 2000, p. 11-36.

MANGABEIRA, W. CAQDAS and its diffusion across four countries: national specificities and common themes. Current Sociology, v. 44, p. 191-205, 1996.

MCKENNY, A. F.; SHORT, J. C.; PAYNE, G. T. Using computer-aided text analysis to elevate constructs an illustration using psychological capital. Organizational Research Methods, v. 16, n. 1, p. 152-184, 2013.

MEYERS, C.; JONES, T. B. Promoting active learning. San Francisco: Jossey Bass, 1993.

MILIKEN, J.; BARNES, L. P. (2002). Teaching and technology in higher education: student perceptions and personal reflections. Computers \& Education, v. 39, n. 1, p. 223-235, 2002.

NOVEMBER, P. Teaching marketing theory: a hermeneutic approach. Marketing Theory, v. 2, n. 1, p. 115-133, 2002.

PECOTCHE, C. B. G. Logosofia: ciência e método. São Paulo: Ed. Logosófica, 2011.

PEIRCE, C. S. Semiótica e filosofia. São Paulo. Cultrix/Edusp, 1975. 
PEREIRA, J. C. R. Análise de dados qualitativos: estratégias metodológicas para as ciências da saúde, humanas e sociais. São Paulo: Editora da Universidade de São Paulo, 2004.

PIAZZI, P. Ensinando inteligência. São Paulo: Aleph, 2009.

REVELL, A.; WAINWRIGHT, E. What Makes Lectures 'Unmissable'? Insights into Teaching Excellence and Active Learning. Journal of Geography in Higher Education, v. 33, n. 2, p. 209-223, 2009.

RICHARDS, L. Qualitative computing - a methods revolution? International Journal of Social Research Methodology, v. 5, n. 3, p. 263-276, 2002.

SILBERMAN, M. Active learning: 101 strategies do teach any subject. Massachusetts: Ed. Allyn and Bacon, 1996.

SINKOVICS, R. R.; ALFOLDI, E. A. Progressive focusing and trustworthiness in qualitative research. Management International Review, v. 52, n. 6, p. 817-845, 2012.

SNYDER, K. D. Ropes, Poles, and Space Active Learning in Business Education. Active Learning in Higher Education, v. 4, n. 2, p. 159-167, 2003.

VALENTE, J. A. (2013). Aprendizagem Ativa no Ensino Superior: a proposta da sala de aula invertida. Disponivel em: <http://www.pucsp.br/sites/default/files/img/aci/27-8_agurdar_proec_textopara280814.pdf>. Acesso em: 12 abr. 2016.

WEITZMAN, E. A.; MILES, M. B. Computer Programs for Qualitative Data Analysis: a software sourcebook. Newbury Park: Sage Publications, 1995. 


\title{
APÊNDICE 1
}

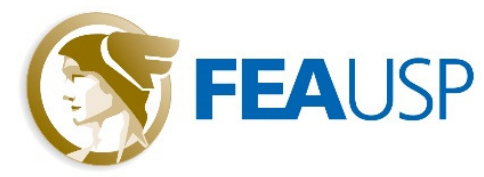

\author{
Programa de Pós-Graduação em Administração \\ Faculdade de Economia, Administração e Contabilidade \\ Universidade de São Paulo
}

Prezado aluno, bom dia.

A presente pesquisa tem o intuito de analisar a metodologia de ensino aplicada na disciplina EAD 0645 Estrutura e Análise de Mercados, oferecida no segundo semestre de 2015.

Este questionário será utilizado em uma pesquisa desenvolvida por alunos e professores do PPGA e tem 0 intuito de propor melhorias para o ensino da FEA/USP.

Por favor, seja sincero e detalhista. Não se limite a respostas "sim" ou "não". Você não será identificado.

Prof. ${ }^{\text {a Dra. Kavita Hamza }}$

Prof. Roberto Falcão

1) De forma geral, qual sua avaliação sobre a disciplina Estrutura e Análise de Mercados, ministrada pela Prof. ${ }^{a}$ Kavita Hamza no semestre passado?

2) Em que área você pretende seguir carreira? Indique sua ordem de preferência, sendo $1 \mathrm{a}$ área preferida e 7 a área menos desejada. Não repita os números, por favor.

\begin{tabular}{|c|c|c|c|l|l|l|l|}
\hline $\begin{array}{c}\text { Ordem de } \\
\text { Preferência }\end{array}$ & & & & & & \\
\hline Área & $\begin{array}{c}\text { Produção ou } \\
\text { Operações }\end{array}$ & $\begin{array}{c}\text { Gestão de } \\
\text { Pessoas }\end{array}$ & Marketing & Finanças & Logística & Vendas & $\begin{array}{c}\text { Administração } \\
\text { Geral }\end{array}$ \\
\hline
\end{tabular}

3) Qual seu efetivo interesse pelos temas (ou algum em especial) tratados na disciplina antes de assistir às aulas (interesse pessoal, interesse profissional, mera curiosidade, nenhum interesse)? Explique. (Lembrando que os temas abordados foram: Design Thinking, Experimentos, Marketing Digital, Vulnerabilidade do Consumidor, Arquétipos, Motivação, Efeito país de origem, Endosso, Público infantil, Sustentabilidade, Ética, Consumo colaborativo).

4) Seu interesse sobre algum dos temas mudou após as aulas? Sobre qual tema? Por quê?

5) Você tinha algum conhecimento sobre algum dos temas abordados na disciplina? Sobre qual tema? Qual o conhecimento? Como você tomou contato com o assunto antes da disciplina?

6) Você acredita que seu grau de conhecimento sobre os temas aumentou após a disciplina? Houve algum aprendizado? Explique.

7) Você se sentiu perdido em algum momento da disciplina e/ou sentiu falta de direcionamento dos professores? Explique.

8) A forma de avaliação de aprendizagem foi adequada (provas, resenhas, artigo final)? Por quê?

9) Em sua opinião, o que funcionou bem na disciplina (forma, conteúdo, atividades, avaliação)?

10) $O$ que você mudaria na forma como a disciplina foi conduzida (forma, conteúdo, atividades, avaliação)? 